\title{
Effectiveness of Concept Mapping's Efficiency in Differential Equations
}

\section{Fatemeh Moradi*}

(iD) https://orcid.org/0000-0001-9609-9057

Tipo de Artículo: Informes de Investigación y ensayos inéditos

Doi: 10.17533/udea.unipluri.20.2.07

Moradi, F. (2020). Effectiveness of Concept Mapping's Efficiency in Differential Equations. UniPluriversidad, 20(2). e2020207. doi: 10.17533/udea.unipluri.20.2.07

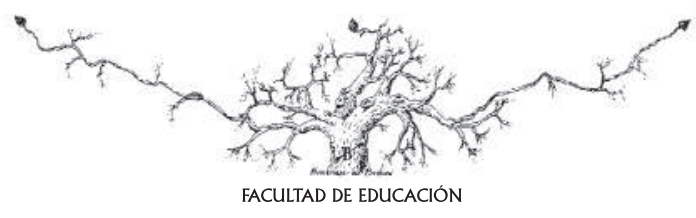

Recibido: 2020-01-04 • Aprobado: 2020-12-22

* Department of mathematics, Yadegar-e-Imam Khomeini (RAH) Shahre Rey Branch, Islamic Azad University, Tehran, Iran.

Email: f_moradi71@yahoo.com 


\begin{abstract}
One of the existing approaches in students' performance evaluation is to use concept mapping. There are lots of studies indicate that concept mappings can be used to evaluate the knowledge of mathematical concepts in a useful way. The best and most comprehensive way of learning is organizing study. Organizing is an expanding meaning strategy. Concept mapping is a simple way to organize and relate information, if vaguely. Lines, words, signs, and symbols are used in concept mappings. In this study, the use of concept mappings in differential equations has been investigated. To do so, a case study of understanding differential equations unit has been conducted in 90 students from Azad University. To begin with, the students went under seven sessions of differential equations of grade one, and another group was taught differential equations in a traditional way. After that, the results obtained were evaluated using SPSS software and Mann-Whitney U test to reach the conclusion. The results indicate the effectiveness of concept mappings. The students show ability to recognize the structure of differential equations that cannot be seen in the results of a traditional teaching method. In addition, the misunderstandings in misconceptions of such structures can be revealed. Therefore, it can be recommended to use the concept maps about differential equations as a complementary assessment tool along with common written tests.
\end{abstract}

Palabras clave: Concept Map, differential equations, meaningful learning, mathematics, teaching. 


\section{INTRODUCTION}

The main strategy of learning and studying is the organization, a kind of semantic expansion strategy. However, the difference with these strategies is that by using an organizational strategy, the learner imposes a framework with organizational structure to the study which covers their learning theorem to make learning meaningful, while such action is not required to be taken in expansion strategies. The simplest form of organization is to categorize the information so it can be learned and remembered (easily). The capacity of short-term memory or active memory is limited; thus, we cannot focus on a large amount of learning material at the same time. Organizing strategy is the ability to arrange or place objects according to the order of a category (Karami Nouri, 2009).

When we categorize several learning materials, we reduce the load on our working memory and improve our concentration. This is the main reason why learning is facilitated by categorizing information. Content categorization is useful for simple or basic topics, while for complex topics, we must use strategies that not only expand active or short-term memory, but also help the learner to make the new information meaningful and keep it in long-term memory in a way that will be accessible and easily retrievable for future use (Seif, 2002).

When the learner faces learning, processing, and thinking problems, we will observe problems in memory, organizing ideas, and thoughts in a meaningful way. This area includes sensory memory, short-term and long-term memory, and thinking. Problems with any kind of memory undoubtedly have an adverse effect on the organization of contents and, consequently, on learning process (Coleman, 2005).

Today, for the purpose of learning from the level of knowledge to the level of thinking and improving the thinking through teaching methods, emphasis has been put on the teaching-learning processes. So, instead of transferring the knowledge through a teacher, a book, and a rote learning, the attention must be paid to the creation of knowledge through meaningful learning. In this regard, the constructivist view of learning emphasizes the active teaching methods that focus on the activity of learners and considers learning as a dynamic and internal process in which learners are actively involved in linking the new information to what they had previously learned to build their knowledge.

Constructivists suggest that the best way of teaching is to determine what the learners have already learned and then to teach from that point (Ausubel et al., 1978). One of the new learning strategies that are consistent with constructivist learning theories (Duffy et al., 1991) or meaningful learning (Ausubel, 1968; Novak, 1991-1992) is the use of a conceptual map. Concept mapping was introduced in the 1980s by Novak (2002), as an instructional tool for coping with rote learning (Novak \& Kenneth, 2006). Concept mapping is based on Ausubel's meaningful learning theory and is derived from Ausubel's concept of advanced organizers. According to Ausubel's view, meaningful learning 
occurs when a learner can organize information and relate new concepts to the previous knowledge in cognitive construction. Cognitive construction is defined as a set of organized information, principles, and concepts that the person has already acquired, and it is assumed to be in the form of a hypothetical pyramid, the top of which contains the more general contents and concepts.

According to the definition by Trochim (1994), concept mapping is an organized process that is focused on an interesting title or structure and includes information from one or more individuals and explores individuals' viewpoints, concepts, and communications through an illustrative concept map. The Concept map is a tool for illustrating the thematic links between concepts in a hierarchical and comprehensive way (Hsu \& Hsien, 2005). Reynolds \& Mojis (2002) consider the concept map as a learning strategy, through which the learner organizes the educational contents in his mind. Regarding this concept map, Eggen \& Kauchak (2001) stated that: "by observing this concept map which illustrates the learner's incomplete understanding, the teacher can help learners by showing and explaining the examples from other closed shapes of circle, pentagon, hexagonal, polygons".

Concept maps show how the relationships between concepts have been shaped in our minds. Concept map is a visual representation of the individuals' knowledge structure about a particular subject, and it is used to assess how students organize their knowledge and provide visible evidence of their understanding. Many researchers have shown the benefits of this form of information presentation and have used concept mapping strategies to see how individuals create their own knowledge about the sub- ject matter (Baralos, 2002). Concept map is generally shown as a powerful learning tool that helps students to explicitly explain their understanding of the subject matter by making relationships between the concepts (Novak, 1972).

Educators have found that a concept map is also a useful tool for assessing students' previous knowledge, diagnosing students' poor understandings, and assisting teachers to identify the key concepts for their own teaching practice. Moreover, as a measurement tool, a concept map determines the level and quality of the new relationship that students can make between concepts after their training (Start et al., 2000).

One of the innovative teaching methods that seems to play a major role in this regard is the concept map approach. The theoretical framework of the concept mapping educational method is based on Ausubel's meaningful learning theory. The Concept map is a graphical tool for organizing and displaying knowledge, which was first developed by Novak (2004) at Cornell University. His curiosity about how students learn helped him to expand concept mapping. Concept maps were first created with the purpose of improving learning, but subsequent studies showed that these maps are useful tools for evaluating, demonstrating students' previous knowledge, summarizing the learned materials, taking notes, assisting students in their studying process, planning, scaffolding, improving understanding, consolidating educational experiences, improving the effective conditions for learning, teaching critical thinking, supporting the cooperative learning, and organizing the content (Saeidi et al., 2012). By describing the concept map, Chiu \& Sun (2004) asserted that a concept map consists of cores and links. Cores in- 
clude a concept, a phrase, or a question that connects to other cores by means of links.

The study results by Morse \& Jurtas (2008) on students in the field of cell biology showed that a concept map with feedback would measurably increase the problem-solving efficiency and reduce the failure rate.

Chiu (2008) explored the impact of concept maps on students' learning and interests. The results of this study revealed that, firstly, the concept mapping based on teaching method had a significant impact on improving student learning compared to the conventional teaching method. Secondly, most of the students were satisfied with the use of concept mapping tools. Duhnck (2009) assessed the learner's level of learning, based on both concept mapping method and traditional method. This study was conducted based on two experimental studies on high school students. The results of the first study showed that concept mapping is an appropriate method for evaluating learners' level of learning. The results of the second study showed that learners with more scientific knowledge show better performance.

Mesrabadi (2008) conducted a study to compare the effectiveness of two methods of preparing concept maps by learners and presenting a pre-prepared map. Findings of this study show that the presentation of concept map-based teaching method has a positive effect on students' academic achievement scores in comparison with conventional methods.

Orhan \& Kavalls (2012) studied the concept map and it revealed a positive impact on students' academic achievement. Erdoğan (2016) conducted a study on An Investigation of the Effectiveness of Concept Mapping on Turkish Students' Academic
Success. Then, he showed the concept mapping instructional strategy has been determined to have a significantly positive effect on the Turkish students' academic success.

Tan \& Sema (2017) conducted a study on concept mapping as a tool to develop and measure students' understanding in science. They showed that this improved their understanding of science, regardless of the scientific content. Kasiyah \& Junus (2018) conducted a study on assessing students' mathematical misconceptions through concept maps and online discussion transcripts: Inner Product Spaces. They identified students' learning difficulties and proposed certain learning activities to help students learn. Moreover, Asmair (2013) conducted a study on student anxiety and the enough writing time; it showed that concept maps can be effective in reducing students' anxiety. Ajaja (2011) researched about the impact of concept map on students' Skill progress in biology. Sakiyo \& Waziri (2015) conducted a study on the effectiveness of concept map in students' progress in biology course. They showed that teaching through concept map can be effective in meaningful learning in the subject of biology. Concept map-based teaching method can have positive impact on increasing learners' academic achievement indicators. On the other hand, due to the large number of technical words and the lack of specific relationships among them, in the course of Biology, the application of concept map in the teaching of this subject can be more effective than using concept map method in the teaching of physics, which has clear concepts and structure of the relationship between these concepts.

It is considered that a concept map has the form of a graph in which concepts are indicated by nodes and the relationships 
among them are indicated by links. The concepts are placed inside a closed geometric shape like a rectangle or a square, and the lines are used to represent the links that connect at least two different concepts to each other. Each of the links and the nodes are signified with a label. A label is a word that is used to give meaning to the concepts and the relationships among them.

Conceptual maps, which are also called network designs, can be drawn in different shapes. The diversity of the way diagrams is displayed, as well as the scientific diversity, has led to the emergence of various types of concept maps, and each of these maps has its own specific characteristics and applications:

Linear Concept Map: Includes nodes and linking lines that continue along each other. This map begins with the first node with the simplest concept, and in the next steps, the complex concepts are placed in the nodes.

Spider-like Concept Map: It is one of the most famous conceptual diagrams. In this type of concept map, the main concept is placed at the center of the frame (node), and the features or the concepts associated with it are represented by arrows (links) and nodes around it.

Circular Concept Map: These types of diagrams are used to represent mathematical and physical concepts that need to be computed and verified by a formula and compensated for the deficiencies in other forms of concept maps. One of the most prominent features of this type of concept maps is the comprehensive and simultaneous presentation of the mathematical concepts and equations.

Networking Concept Map: These maps are considered as complicated maps in which, to transfer more networking concepts, each node can be connected to other nodes via a link and thus provide more details of the related issues. The networking design can be drawn in a variety of ways and has a specific application. One of these models is a radial model. In this model, the main title is in the middle of the concept map's frame, the main branches are located around the main title and subbranches are linked to the main branches. As the method used for this study, the radial model of the networking concept map was used as it is shown in Figure 1.

Presuming that the knowledge is organized based on some known central concepts in a content domain, implies the existence of a highly integrated conceptual structure which exists among the concepts: Concept maps are well known as a more direct approach to detect the interrelationships between the concepts in a limited area. Formally speaking, a concept map is a graph that contains several labeled nodes and lines as represented in Figure 1. The nodes indicate the concepts in the form of key terms in a limited area. The relationships among different pairs of concepts are indicated by the nodes. The label of each line displays the kind of relationship between each pair of concepts. A set that contains a labeled line and two nodes is known as a proposition. A proposition is made up of a combination of the basic unit of meaning in a concept map and the smallest unit which can be used to make a judgment about the validity of the relationships among the concepts (e.g., Dochy, 1996). While the concept maps potentially may be used as the structural assessing tool of the student's knowledge, it has more frequently applied as instructional tools (Ruiz-Primo \& Shavelson, 1996a). An example of both uses: 


\section{Figure 1}

Networking concept map (adapted from Ruiz-Primo, 2000).

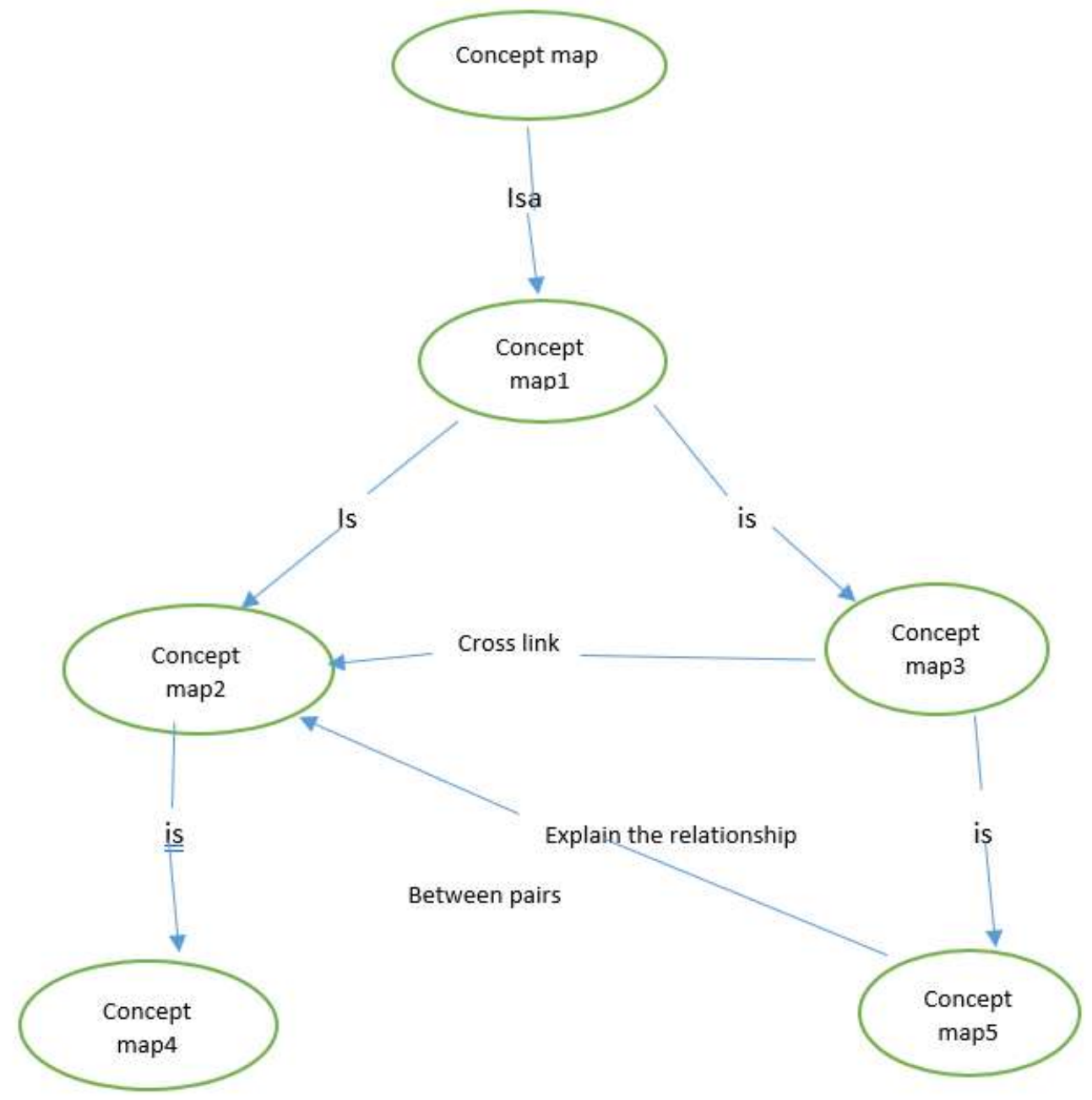

Most of the books on differential equations emphasize conceptual teaching. With the advancement of technology and the emphasis on teaching the nonlinear differential equations, differential equation systems, mathematical modeling, and algebraic, numerical, and qualitative approaches, we can address and involve in the conceptual teaching of the differential equations. Analytical techniques for solving differential equations are still important. However, the focus of the solutions is not just on them. Therefore, by the opening of new paths, much attention has been paid to conducting the research to clarify the conceptual learning and teaching dimensions of differential equations (Rasmussen \& Whitehead, 2003). By the Study on the procedural learning and conceptual learning, Arsalan (2010) noted that the traditional and the dominant methods of mathematics education. Hence, the teaching of differential equations is mostly procedural. He concluded that the procedural learning of differential equations does not guarantee the conceptual learning. He considers the type and nature of errors in solving differential equations as one of the criteria for the separation of procedural learning and the con- 
ceptual learning of differential equations. He believed that the differential equations are an influential course in academic. Today, students receive in courses such as differential equations, they play an important role in the promotion and productivity of the entire mathematics education system.

On the other hand, it can be said that the approach to teaching differential equations is often a traditional approach (Hebreh, 2010). This approach is presented in an abstract world, which has no connection with the real world of learners, and it is characterized by the focus on conducting only algebraic analysis and paying less attention to their usages. In this approach, the teachers are expected to teach directly and provide a standard algorithm for the learners to solve every famous differential equation. Learning in this approach is mostly reliant on repetition and practice, and most of the learners' activities are based on memorizing patterns or algorithms. In the traditional approach, the main challenge appears when learners face other problems than those that they have already been learned, and they should adopt and apply an appropriate method for dealing with it. Based on the investigations by Herb (2010) on traditional instruction of differential equations and conceptual learning with the aim of exploring the nature of students' learning in traditional differential equations (DEs) courses, it was concluded that learning about this method is mostly relied on repetition and practice, and most of learner's activities are based on algorithms or algorithm maintenance patterns.

This issue can bring more difficulty when the learner encounters an unusual problem. Therefore, the learners should recognize that researching on a difficult problem may require Algebraic analysis, computation, and an appropriate judgment to determine the best tool for a specific purpose.

Therefore, considering that one of the units in the fields of engineering is the lesson of differential equations and since this course unit has well-defined lessons and each lesson has a special and distinct methodology, so that students are weak in recognizing the contents and applying the appropriate strategies to solve problems because they have challenges and misunderstandings on initial calculations of derivative and integral, the concept map helps to solve these challenges and eliminating misunderstandings and errors. Moreover, students should deeply and fully understand the subject contents to provide an appropriate solution. According to Komachu et al. (2012), one of the challenges that engineering students face in the algebraic approach to differential equations is diagnoses and calling the most appropriate strategy to solve the differential equation.

Educational success in mathematics courses as a prerequisite for academic success in specialized courses in engineering majors is of particular importance, because firstly, academic success is one of the components of social status and secondly, it has a direct and high impact on an individual's position and status in the structure of his career and income (Khodaie, 2010.) Academic failure in mathematics can hinder the academic achievement of engineering students. In this regard, Lopes believed that the concern of academic failure has an unpleasant impact on the students (Lopes, 2012).

Arsalan (2010) reviewed the exam papers of 77 science and engineering students and noticed that with traditional methods 
of teaching differential equations, students may seem successful, while this success might have been achieved without conceptual understanding of differential equations. Arsalan emphasized the need to use new methods of teaching differential equations for engineering students. In this regard, Komacho et al. (2009) reviewed the answer sheet responses of 21 science and engineering students. They categorized students' errors in eight different ways and emphasized that in order to achieve modeling skills and competencies, we must address and study the students' errors in solving differential equations.
Sánchez (2012) studied a sample of 18 engineering students at a Spanish state university. As he noted, it must be acknowledged that engineering students make mistakes when solving differential equations.

Therefore, considering this need, the researcher seeks to examine whether concept map is effective in optimal learning of the first order and second order differential equations or not.

According to the explanations above, the main question of this research is that whether using concept map has any effect or efficiency on students' learning in differential equations or not.

\section{METHOD}

\section{口-}

In this study, the quasi-experimental method was used. The required instruments in this study which were pre-test and posttest were used along with measuring the validity and reliability of the tests. At first, after selecting about 35 students, the researcher implemented the pre- and post-test on the selected sample, and then using content validity, the opinions of experts in the field of mathematics education were recorded and the questions were approved, and then based on data analysis with Cronbach's alpha in two repetitions of the test at specified intervals, an acceptable value above $70 \%$ was obtained to establish reliability.

In both groups, the first-order differential equations including the methods of segregation, homogeneous, non-homogeneous, complete, incomplete, first order, and Bernoulli were taught. In control group, given that for selection of sample, the sample was selected from those who showed mathematical performance in the current semester in a range from average to weak and average to high, it was tried to select two groups of control and experimental regarding the selection of a range of these subjects in the sample with a variety of different mathematical performances. The materials were traditionally and routinely taught by presenting the methods. In the experimental group, the teaching was conducted through the concept mapping using a radial model of networking method. The radial model of networking method in the first-order and second-order differential equations lesson is presented in figures 2 and 3.

This study included an independent variable with two levels (using a concept map and not using a concept map) that the effect of using this variable on the students' academic achievement scores in recalling and understanding the concepts of differential equations (as dependent variables) was examined. The whole research process was conducted in the four stages below: 
Preparation stage: The preparations for the experiment were provided. Once the samples were selected, the content to be taught was first determined using the concept mapping method.

Pre-test stage: At the beginning of the study, a pre-test of derivative and integration methods was administered to all classes of differential equations courses.

Implementation stage: The duration of the research was seven sessions of 120 minutes' each. In these sessions, the professor presented the lesson with a concept map and maps were used as a pre-organizing tool before training, content presenting tool. During the training, and a tool for summarizing and integrating the lesson after training.
Post-test stage: At the last session of the experiment, a test (post-test) was administered to the participants without prior notice to measure the subjects' learning from the trained contents during the study. With religious minorities and with respect to the ethnic culture in a city. Racial-ethnic prejudices were observed in this study.

After the experimental and control groups were identified at the university, the educational content that will be taught in class sessions was determined for all training classes. The instructors of the control group used conventional methods for teaching in their classrooms and teaching sessions. The experimental group instructors also used concept mapping method for teaching in the 7 sessions of their classes. Pre-test and post-test were taken before and after the stage of teaching.

\section{Participants}

The population included the engineering students of Islamic Azad University. 90 students who had the differential equation course unit were selected to participate in the study and the methods and tests were implemented on the samples. In this study, a random sampling method was used. For this purpose, 90 students from technical and engineering faculty were considered as the available samples. In this study, the subjects participated in two experimental groups and one control group. The population included all engineering students 40 of which were assigned to the experimental group and 50 students were assigned to the control group. In the experimental group, teaching was through concept mapping method and in the control group the teaching was through traditional method. At the beginning of the study, a pre-test was administered to the ex- perimental groups. Figure 2 shows the concept map of the first-order differential equation and Figure 3 shows the concept map of the second-order differential equation.

In Figure 2, the concept map of first-order linear differential equations, includes: separable, homogeneous, and heterogeneous (two parallel lines and two intersecting lines), complete, incomplete (a function of $\mathrm{x}$, a function of $\mathrm{y}$ and a function of $\mathrm{x}, \mathrm{y}$ ), first-order linear, and Bernoulli equations.

In Figure 3, the concept map of second order linear differential equation includes: homogeneous equation (characteristic equations: with distinct roots, equal roots, non-real roots), heterogeneous equation (indeterminate coefficients, parameter change), and Cauchy-Euler equation (homogeneous (characteristic equation with: distinct, equal, mixed or unreal roots) and heterogeneous. 
In the first figure, the concept map of first-order linear differential equations includes the separable equation homogeneous equation which finally turns to separable equation, heterogeneous which divides into two states: in the first state, the coefficients $\mathrm{dx}$, dy are two parallel lines, and in the second state, they are two intersecting lines. Following this calculation, the heterogeneous equation turns into homogeneous equation and then turns into a separable equation; an incomplete equation turns into a complete equation by the functions of $h$ (x), h (y), h (x, y); and Bernoulli turns into the first-order linear equation. In the second figure, the concept map of second order dif- ferential equations includes: homogeneous equation which turns into a characteristic equation with the following three parts: 1 . distinct roots, 2. equal roots, 3. non-real roots, heterogeneous equation that includes indeterminate coefficients and parameter change, Cauchy-Euler equation which includes two parts of homogeneous (that has a characteristic equation with three status of: 1. distinct roots 2.equal roots, and 3. mixed or unreal roots) and heterogeneous.

Laplace concept map which includes Laplace transform, integral, derivative and integral function, and inverse Laplace which includes the related theorems are included in the appendix.

\section{Figure 2}

First-order differential

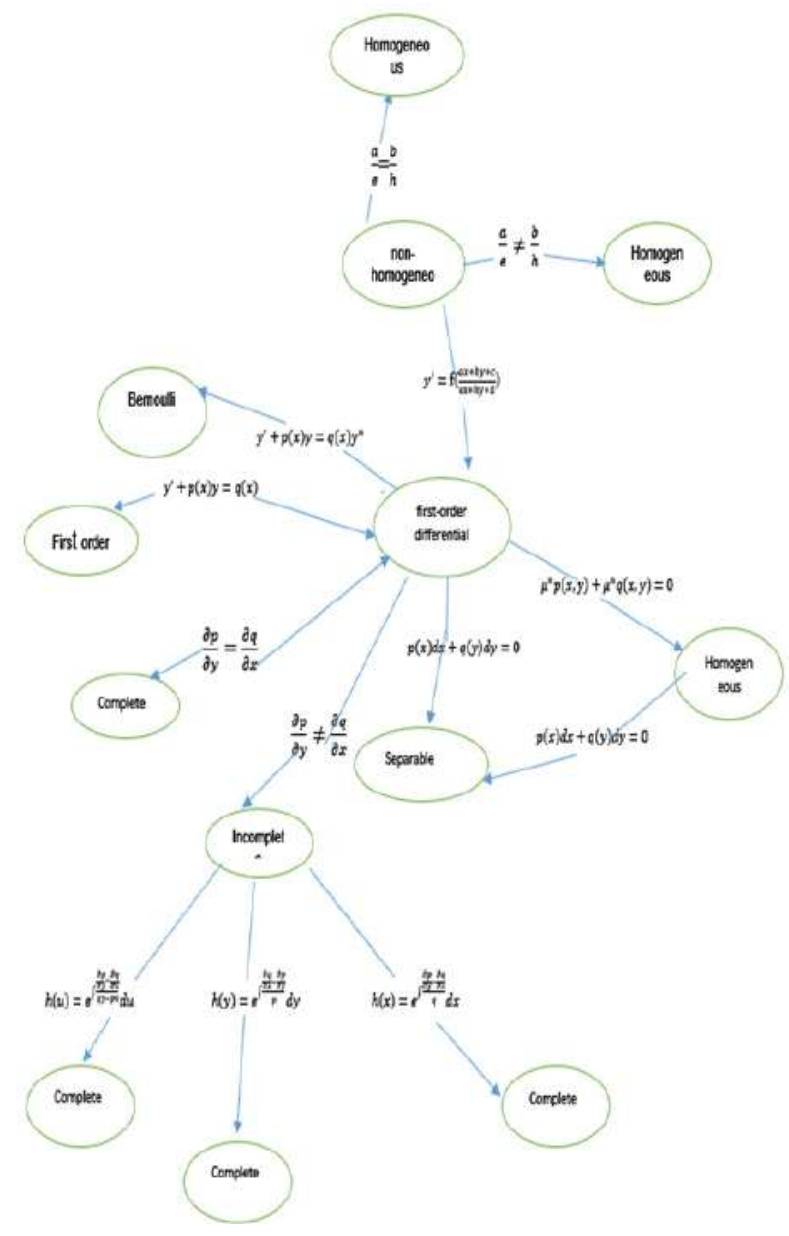




\section{Figure 3}

Second-order differential.

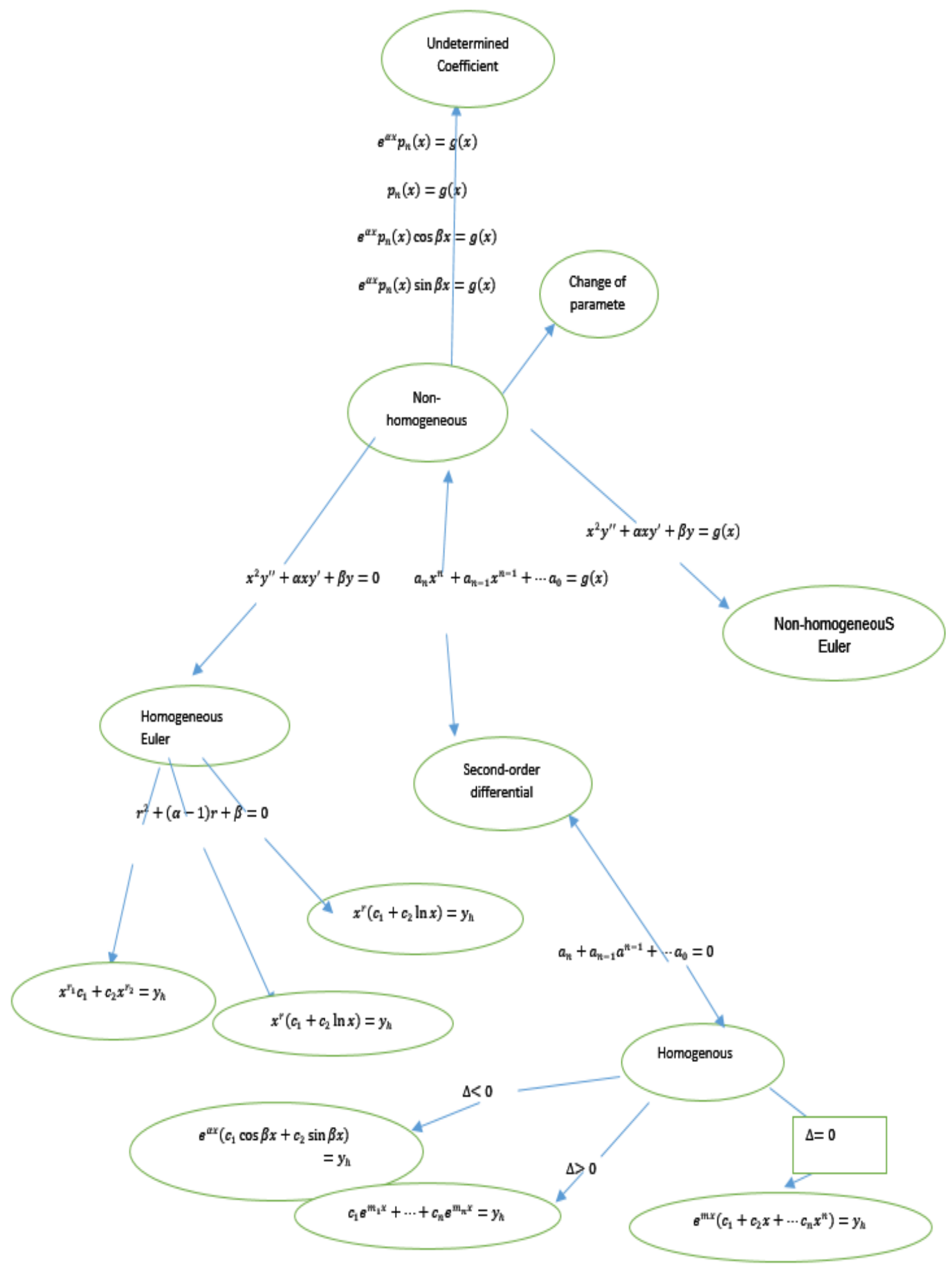




\section{INSTRUMENTS}

In this study, the researcher-made academic achievement tests from all the contents of the differential equations course and materials, taught through concept mapping method and conventional methods from the differential equation pamphlets and lecture notes were used during the research period to measure students' level of learning. A pre-test and a post-test were used as the research instruments in this study. The pre-test was from the content of derivation lesson and integration methods. The post-test was also prepared from the trained contents of the firstorder differential equations (in 7 sessions) with concept mapping and conventional methods.

Apre-test and a post-test were administered to the students. The pre-test was administered right at the first week of instruction at the beginning of the semester in 2017. The questions in the pre-test were the problems including the derivatives of differentiation of trigonometric functions, inverse trigonometric functions, the exponential and logarithm functions, and integral problems in the fields of integration methods (change of variables, integration by parts, rational and trigonometric fractions). The post-test was administered at the eighth week of instruction in the first semester of 2017, consisting of 4 questions. This test, which includes the questions from the first order differential equations, covers 5 points of the final exam grade. To verify the validity and reliability of the questions, a sample of 20 students was selected in the second semester of 2016 and the questions were applied to them, through the SPSS software and using Cronbach's alpha, the value of 0.75 was obtained.

\section{FINDINGS}

口

To explore the questions above, we first examine whether the data is normal or not. For this purpose, we use Kolmogorov test.

In general, data was not normal. Since data was not normal, it is possible to run the Mann-Whitney U test.

Table 1 Descriptive statistics.

\begin{tabular}{|c|c|c|c|c|}
\hline & & $\mathrm{N}$ & Mean & STD \\
\hline \multirow{2}{*}{ Control } & Pretest & \multirow{2}{*}{50} & 1.50 & 0.25 \\
\hline & Posttest & & 2.01 & 1.35 \\
\hline \multirow{2}{*}{ Experiment } & Pretest & \multirow{2}{*}{40} & 1.72 & 0.51 \\
\hline & Posttest & & 3.23 & 1.18 \\
\hline
\end{tabular}

The participants of this study included two groups of 40 students from the experimental group and a control group of 50 students. The first group was labeled code 1 and the second group was labeled code 2. Table 1 indicates that the mean of the experimental group in the post-test was greater than the mean of the control group in the post-test. 
Table 2. U-Mann-Whitney test.

\begin{tabular}{|c|c|c|c|c|}
\hline & $\mathrm{N}$ & Mean & Mann Whitney U & $P$ \\
\hline Experiment & 40 & 28.95 & 250.00 & $0.001^{*}$ \\
\hline Control & 50 & 46.11 & & \\
\hline
\end{tabular}

According to Table 2, the mean rank of the experimental group is higher than the control group. Moreover, the results of Table 2 for the U-Mann-Whitney test show that there is a significant difference between the control and the experimental group $(\mathrm{p}<0.05)$. Alternatively stated, the experimental group has a higher mean rank compared to the control group. According to the obtained results, the answer to the first question is that teaching through concept map can be effective because the mean score of the class which had led through concept mapping teaching method is completely different from the class that had been led through traditional teaching method. Moreover, these results show that teaching through concept mapping teaching method is more meaningful. In other words, teaching through concept mapping method is more effective for students, which means that learning can take place better through this method. In this regard, Hatami, Abbasi and Abdullah Mirzaei (2009) believed that in a regular teaching practice, the presentation of a concept map before the teaching begins, plays the role of a pre-organizer. Moreover, presenting or providing a concept map after learning takes place, can provide learners with a summary of what has been learned. They also asserted that the concept map helps learners to organize complex topics in an understandable and comprehensive framework, thereby contributing to meaningful learning. Some of the student's handwriting are presented:

Figure 4: Student's answer script-sample 1.

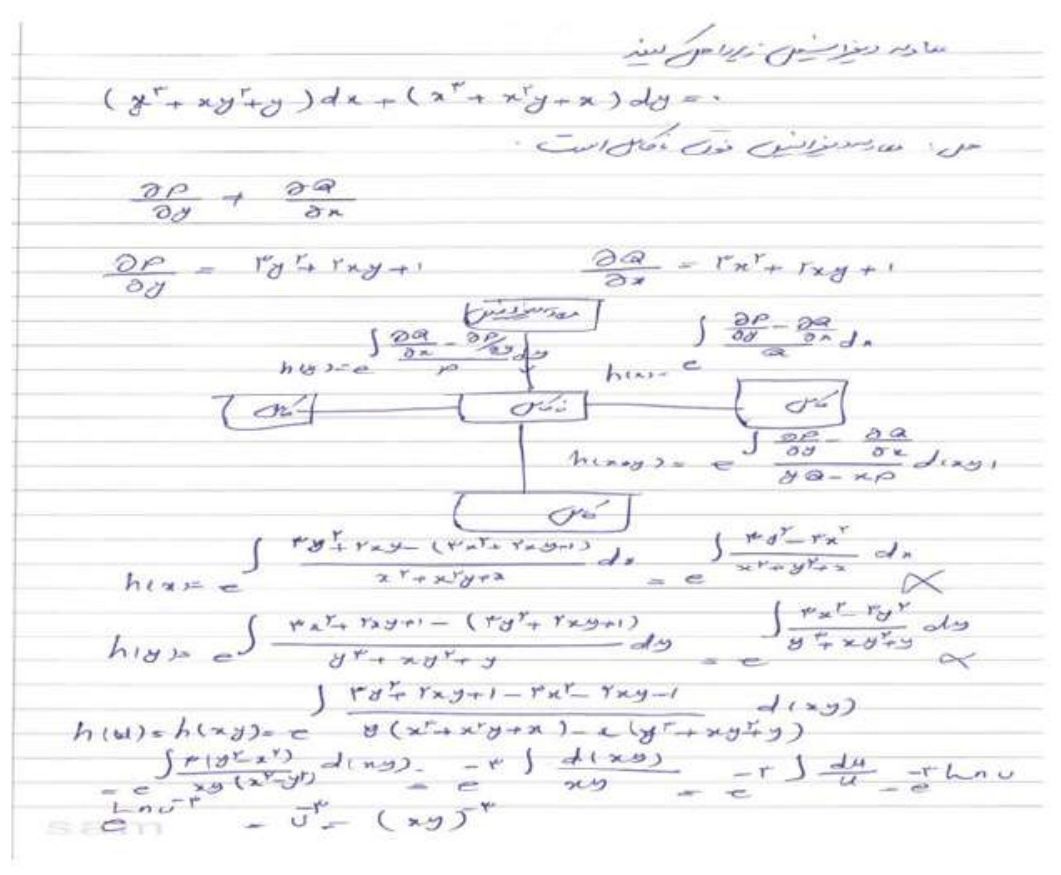


In the first answer script (Figure. 4), the student firstly recognized that the equation above was incomplete. Then he wrote the equation relation of the incomplete equation:

$$
\frac{\partial p}{\partial y} \neq \frac{\partial q}{\partial x}
$$

And then he drew the concept map associated with the incomplete first-order differential equation and, according to the concept map model, he tested all three integral factors- that are:

$$
\begin{gathered}
h(x)=\int \frac{\frac{\partial p}{\partial y}-\frac{\partial q}{\partial x}}{q} d x \\
h(y)=\int \frac{\frac{\partial q}{\partial x}-\frac{\partial p}{\partial y}}{p} d y \\
h(x y)=\int \frac{\frac{\partial p}{\partial y}-\frac{\partial q}{\partial x}}{q x-p y} d x y
\end{gathered}
$$

Each factor individually and ultimately reached the main and correct answer. Given that initially a pre-test involving the area of integration methods was administered, this learner was somehow successful in using integration techniques in this test, it is he was successful on both, identifying the method of integration and in its algebraic parts. Similar to George Polya's problem solving model, the following four-step model with the acronym of BAFT was introduced for analysis in solving differential equations:

Diagnosis (of a differential equation)

Calling (the most appropriate strategy to solve the differential equation)

Running (the called strategy)

Review (of the implemented strategy)

According to George Polya's model, it can be said that considering the diagnosis of a differential equation, the student recognized that it was a first-order equation, for calling the most appropriate strategy to solve the equation, he selected the incomplete differential equation strategy and considering the implementation of differential equation strategy he could successfully solve the equation.

Figure 5: Student's answer script- sample 2.

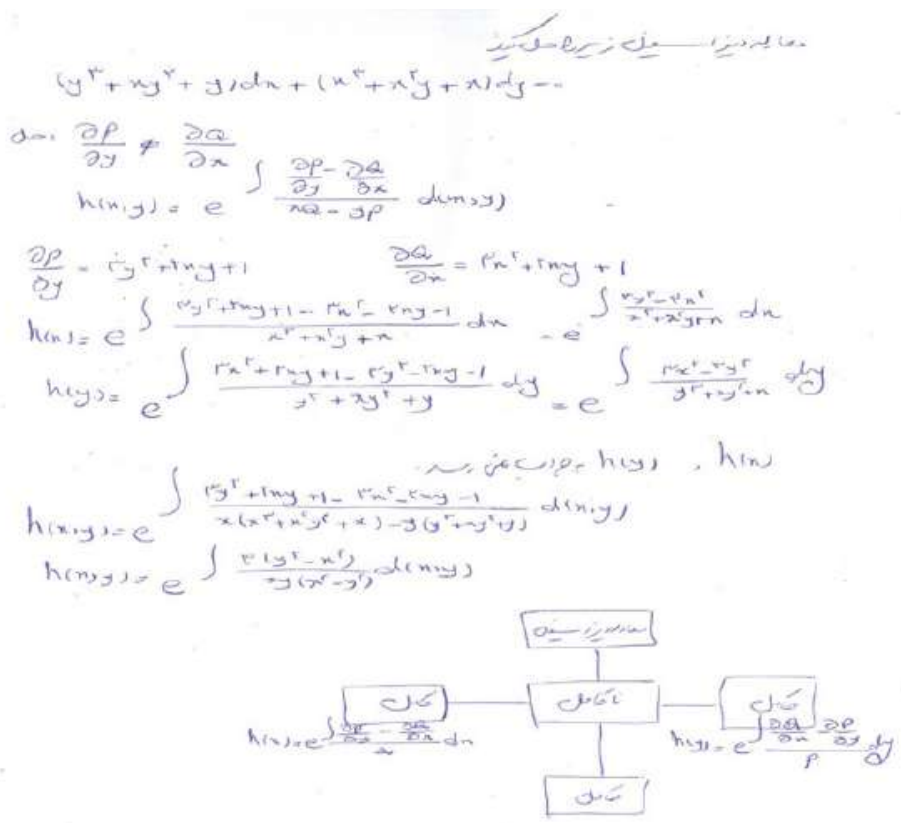


In the second answer script (Figure. 5), the student firstly recognized that the differential equation was incomplete. He wrote the equation relation of the incomplete equation and then he drew the concept map associated with the incomplete first-order differential equation, and then according to the concept map model, he tested all three integral factors, the result of which was a failure in the first integration factor.

$$
\begin{aligned}
& h(x)=\int \frac{\frac{\partial p}{\partial y}-\frac{\partial q}{\partial x}}{q} d x \\
& h(x)=e^{\int \frac{3 y^{2}-3 x^{2}}{x^{3}+y^{2}+x} d x} \\
& h(x y)=\int \frac{\frac{\partial p}{\partial y}-\frac{\partial q}{\partial x}}{q x-p y} d x y=\int \frac{3\left(y^{2}-x^{2}\right)}{x\left(x^{3}+x^{2} y+x\right)-y\left(y^{3}+x y^{2}+y\right)} d(x, y)
\end{aligned}
$$

The learner then tested the second factor which is shown in the concept map, in other words, the learner placed it in the second factor formula.

$$
h(y)=e^{\int \frac{3 x^{2}-3 y^{2}}{y^{3}+x+x y^{2}} d y}
$$

Finally, the integral expression is formed by both $\mathrm{x}$ and $\mathrm{y}$, which indicates that the learner had to give up this factor and then used the third factor which he had identified its concept map, that is, he placed it in the

Figure 6: Student's answer script-sample 3.

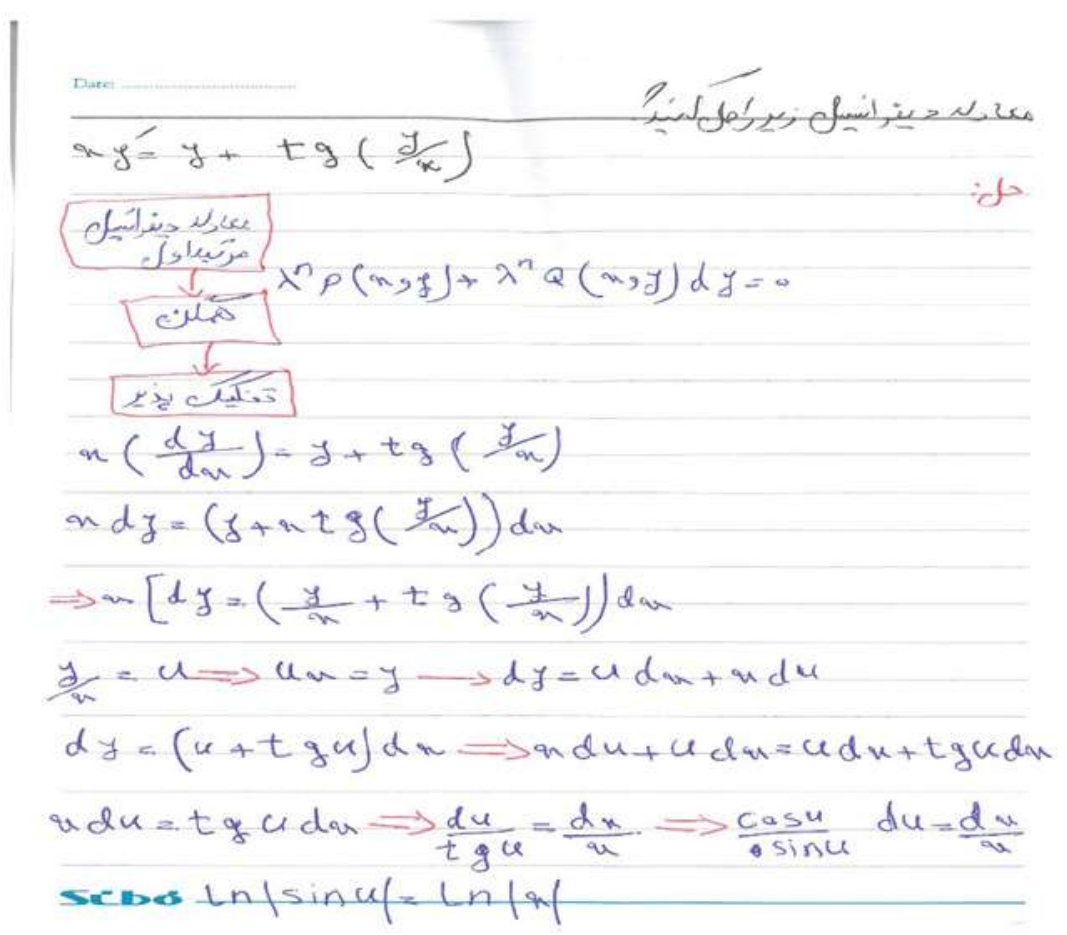

But because he is weak in algebra, he did not reach the answer which should be an expression in terms of $\mathrm{x}$ and $\mathrm{y}$. He failed in solving the problem, but we cannot say that the learner was unable to identify the solution of the equation, instead we can say that he was weak in solving the algebraic expression. In the integral pre-test this learner 
was successful in identifying the integration method, but he was weak in algebraic relations. According to George Polya's model, it can be said that the student was successful in the first step which is diagnosis, because he recognized that the differential equation was of the first order type; he was also successful in the step of calling for the most appropriate strategy to solve the equation, because he selected the best strategy to solve the differential equation, which was the incomplete differential equation, but in the step of running the called strategy he was not successful because he made an algebraic mistake in solving the equation.

In the third answer script, the learner recognized that the first-order linear differential equation was of homogeneous type and drew the corresponding concept map. He performed the steps one by one, that is, he first examined the equation to check its homogeneity condition and found that it was a homogenous equation, that is: $\lambda^{n} \mathrm{p}(\mathrm{x}, \mathrm{y}) \mathrm{dx}+\lambda^{n} q(x, y) d y$. Then he used the homogeneous method for the above equation. It means that he first created the $\frac{x}{y}$ variable, and then he used the change of the $u=\frac{x}{y}$ variable:

$$
\begin{aligned}
& x\left[d y=\left(\frac{y}{x}+\operatorname{tg} \frac{y}{x}\right) d x\right] \\
& d y=(u+\operatorname{tg} u) d x \\
& x d u+u d x=u d x+\operatorname{tg} u d x \\
& x d u=\operatorname{tg} u d x
\end{aligned}
$$

He transformed the equation into a separable equation and ultimately reached the correct and fin al answer:

It has nothing to do with solving an equation and finding an appropriate method. He had algebraic errors during the solving process which was due to the learner's misunderstanding and lack of correct comprehension. For example:

$$
x\left[d y=\left(\frac{y}{x}+\operatorname{tg} \frac{y}{x}\right) d x\right]
$$

The learner, regardless of the $\mathrm{x}$ that he had factored out, ignored the $\mathrm{x}$ on both sides of the equation which were eliminated. This indicates the weakness of the learner in solving the algebraic relations. The learner was somewhat successful in the pre-test on integrating methods. That is, he was successful in identifying the integrating method, but he was weak in the algebraic parts.

\section{DISCUSSION AND CONCLUSION}

The main theory behind the conceptual map is the meaningful learning theory of Ausubel. David Ausubel was a psychologist who made a distinction between rote learning and meaningful learning. Based on Ausubel's theory, the cognition structure and the changes that take place as result of learning, form the basis of learning. In this theory, cognitive structure is a set of organized information, concepts, principles, and generalizations that we have already learned in one of the disciplines of knowledge. In this pyramid or cognitive structure hierarchy, every content is more general, abstract, and concise than the contents which lay below it (Seif).

Regarding the impact of this method on the meaningful learning dimension (high-level perception), it can be asserted 
that learners who go under the concept mapping curriculum (presentation and construction) will be more successful in achieving higher levels of Bloom's taxonomy (1975).

Most of engineering students experience academic failure in their university mathematics courses such as differential equations. Several factors can contribute to the academic failure in mathematics courses. One of the causes of academic failure can be the errors and mistakes that students make in solving differential equations. Similar to George Polya's problem-solving model, in order to analyze the errors in solving differential equations, the following four-step model can be presented. With regard to the students' mistakes and errors in solving the differential equation, the researchers considered two groups in this study: 1- Experimental group, in which teaching took place through the use of concept mapping method and the second group as the control group, in which the teaching took place by the use of traditional method. For this purpose, six classes of differential equations with total number of 90 students were selected from the Islamic Azad University. 40 learners were undergone the instruction through concept map and 50 students were trained through conventional teaching method during seven session. During the 7 training sessions, the first-order differential equations were taught to a group of students through concept mapping method, and the differential equations were being taught to the other group through conventional method. After administrating the test to the students, the results were analyzed through Mann-Whitney U test. According to the results of statistical analysis, it was observed that in experimental group, students made less errors in the steps such as diagnosis, calling and running the appropriate strat- egy in solving the differential equation compared to the control group; and most of the students' errors in this group were algebraic errors, while in control group most of the mistakes were in the first and second steps including diagnosis and calling the most appropriate strategy to solve the differential equation as well as the algebraic errors.

This study examined one of the usages of the concept maps in learning, in that it can be useful by being applied to the lesson of differential equations, in calling and diagnosing the differential equation. Given the large number of contents regarding the differential equations, concept mapping can be an appropriate way to memorize and remember the material by the learners. Likewise, based on the theories of information processing, it can be highly expected that the use of concept maps has a positive impact on the processes of memorizing and remembering the materials. Moreover, concept maps can be appropriate cognitive and metacognitive tools. Since Seif (2002) has introduced learning strategies with two terms of cognitive strategies and metacognitive strategies. Cognitive strategies are actions by which individuals prepare new information to be linked and integrated with previously learned information and to be stored in longterm memory (such as rehearsal or repetition, review, expansion, organization, etc.). In contrast, metacognitive strategies are measures that monitor, control, and direct cognitive strategies (e.g. planning, evaluation, regulation). It is assumed that cognitive strategies lead to cognitive development and metacognitive strategies lead to monitoring and controlling cognitive progress.

Concept mapping has been emphasized as a teaching, learning and evaluation tool. 
Given that differential equations should be taught in different groupings and that finding the groupings for engineering students is somehow complicated, it seems that the cognitive structure of students should be determined and recognized in a systematic way. Therefore, this study was conducted by investigating the present situation of the concept map issue in solving the differential equations. On the other hand, it can be said that in drawing the concept map, the learners put the acquired knowledge into the context of their intended and familiar concepts, and these two factors make it easier for the learner to classify the new information and put them under each other, the likelihood of the relationship between new concepts and the previous concepts also increases, and, in general, it leads to the increase in the learner's understanding of the created rela- tionship. The present study came to the results that were similar and in consistence to the findings by Orhan and Kavalls (2012), Yavuz Erdoğan (2016), Tan \& Sema (2017), Sakiyo \&Waziri (2015), and Kasiyah Junus (2018). Based on the findings of considering the suggestion for further research, it is suggested to conduct a study on the possibility of using concept map as an evaluation tool, and on evaluating their scoring and rating methods. It can also be suggested to investigate the use of concept mapping method in other mathematical lessons. Concept maps can be used to teach other parts of differential equations such as Laplace's method. On the other hand, concept mapping method can be used in teaching the related lessons in engineering courses such as telecommunications fields to help learners better understand the main and basic lessons.

\section{REFERENCES}

Asmari, A. A. (2013). Investigation of writing strategies, writing apprehension and writing achievement among Saudi EFL-major students. International Education Studies, 6(11). http://dx.doi. org/10.108/01463378109369412.

Ajaja, O. P. (2011). Concept Mapping as a Study Skill: Effects on Students Achievement in Biology. Int JEdu Sci, 3(1): 49-57

Arslan, S. (2010). Traditional instruction of differential equations and conceptual learning. Teaching Mathematics and its Applications, 29(2), 94-107

Ausubel, D. P., Joseph, N., \& Helen, H. (1980). Psychologies des Unretracts. Wenham und Basel: Beltz Verlag.

Ausubel, D. P., Novak, J. D., \& Hanesian, H. (1978). Educational Psychology: A Cognitive View (2nd ed.). New York: Holt, Rinehart and Winston.

Baralos, G. (2002). Concept mapping as evaluation tool in mathematics. Paper presented at the 2nd International Conference on the Teaching of Mathematics

Boyce, W. E., DiPrima, R. C., \& Mitrea, D. (2010). Elementary differential equations and boundary value problems, Wiley

Bloom, B. S. (1975). Human characteristics and school learning. McGraw-Hill

Chiu, Ch. (2008). The effect of concept mapping on students learning achievements and interests. Innovation's in education and teaching international, 45(4), 38-53. 
Chiu, C.-H. (2004). Evaluating system-based strategies for managing conflict in collaborative concept mapping. J. of Computer Assisted Learning, 20, 124-132.

Camacho, M., Perdomo, J., \& Santos, M. (2012), An exploration of students' conceptual knowledge built in a first ordinary differential equations course (part I), The Teaching of Mathematics, Vol. xv, pp. 1-20.

Coleman, L. J. (2005). Nurturing talent in high school: Life in the fast lane. Teachers College Press New York, NY

Dahncke, H. (2008). Testing achievement with concept mapping in school physics. Conference of concept mapping Tallinn, Estonia \& Helsiniki, F.

Dochy, F. J. R. C. (1996). Assessment of domain-specific and domain-transcending prior knowledge: Entry assessment and the use of profile analysis. In M. Birenbaum \& F. J. R. C. Dochy (Eds.) Alternatives in assessment of achievements, learning process and prior knowledge (pp. 93-129). Boston, MA: Kluwer Academic Publishers.

Duffy, T. M., \& Jonassen, D. H. (1991). Constructivism: New implications for instruction technology. Educational Technology, 31(3), 7-12

Eggen, P., \& Kauchak, D. (2001). Educational Psychology (5th ed). Upper Saddle River.NJ: Merril/ Prentice.

Erdoğan, Y. (2017). An Investigation of the Effectiveness of Concept Mapping on Turkish Students' Academic Success. Journal of Education and Training Studies, 4(6), 1-9

Goldsmith, T. E., Johnson, P. J., \& Acton, W. H. (1991). Assessing structural Knowledge. Journal of Educational Psychology, 83(1), 88-96.

Hsu, L., \& Hsien S. (2005). Concept maps as assessment tool in a nursing course. Journal of professional Nursing, 21(3), 141-149.

Habre, A. (2010). Traditional instruction of differential equations and conceptual learning. Teaching Mathematics and Its Applications, 29, 94-107.

Hatami, J., Abbasi, R., \& Mirzaei, A. (2009). Improving the quality of teaching concepts. Journal of Educational Technolog, 3(4), 281-296

Kasiyah, J. (2018). Assessing Students' Mathematical Misconceptions through Concept Maps and Online Discussion Transcripts: Inner Product Spaces, Proceedings of the 26th International Conference on Computer sin Education. Philippines: Asia-Pacific Society for Computers in Education.

Khodaie, E. (2010), Effective factors on passing in national entrance exam in7. Postgraduate level. Quarterly Journal of Research and Planning in Higher Education, 15(6), 19-34.

Kavak, K. (2012). Illkögretim 8. sinıffen ve teknoloji dersi 'maddenin halleri ve ısı' ünitesinde kavram haritası tekniği kullanımının öğrencilerin başarısına, bilgilerin kalıcılığına ve fene karşı tutumlarına etkisi. Doctoral Dissertation, Atatürk University, Erzurum.

Karami, R. (2009). Psychology of memory and learning with cognitive approach. Samt.Tehran

Lopes, M. C. \& Fernandes, G. L. (2012), A comprehensive approach towards academic failure: the case of mathematics I in ISEG graduation, European education research conference education, Development and Freedom, Universidad of Cadiz. 
Morse, D. \& Jutrus, F. (2008). Implementing Concept-based Learning in a Large Undergraduate Classroom. CBS 2008 Summer; 7(2): 243-253.

Msrabady, J. (2008). the effects of concept mapping (presentation and construction learners' entry characteristics on cognitive performance - emotional learning biology. Ph.D. Thesis. Tabriz University.

Novak, J. D. \& Cañas, A. J. (2008). The theory underlying concept maps and how to construct and use them. Journal of Research in Science Teaching, 28, 10. Technical Report IHMC Campstools. Florida Institute for Human and Machine Cognition. Retrieved May18, 2014 from http://www. ssu.ac.ir/fileadmin/templates/fa/Moavenatha/Moavenate-Amozeshi/edicupload/olymp-3.pdf.

Novak, J.D. \& Canas, A.J. (2006). The origins of the concept mapping tool and the continuing evaluation of the tool. Information Visualization Journal, 5(3), 108-132.

Nancy, L. G. (2013). Concept mapping for learners of all ages, Journal for Educators, Teachers and Trainers, 4 (1), 59-72.

Novak, J.D. (2002). Meaningful learning: the essential factor for conceptual change in limited or appropriate Propositional hierarchies (LIPHs) leading to empowerment of learners. Science Education, $86,548-571$

NCTM (National Council of Teachers of Mathematics). (1995). Principles to actions: Ensuring mathematical success for all. Reston, VA: NCTM

Orhan, A. (2012). Alternatif ölçme ve değerlendirme etkinliklerinin 6. sınıf fen ve teknoloji dersi yaşamımızdaki elektrik ünitesindeki öğrenci başarısına etkisi. Master's Thesis, Ahi Evran University, Kirşehir.

Reynolds., J. A.\& Thompson, R. J. (2002). Want to improve undergraduate. Thesis writing engage students and their faculty readers in scientific peer review.

Rasmussen, C., and K. Whitehead. (2003). Learning and teaching ordinary differential equations. MAA Online Research Sampler. Retrieved January 2013 from: http://calculus- course.maa.org/t and_1/sampler/rs_7.html\#support.

Rasmussen, C. L. (2001). New directions in differential equations a framework for interpreting students' understandings and difficulties. The Journal of Mathematical Behavior, 20(1), 55-87

Ruiz-Primo, M. A. \& Shavelson, R. J. (1996a). Problems and issues in the use of concept maps in science assessment. Journal of Research in Science Teaching, 33(6), 569-600.

Sakiyo,J. \& Waziri,K.(2015). Concept Mapping Strategy: An Effective Tool for Improving Students' Academic Achievement in Biology. Journal of Education in Science, Environment and Health. (JESEH), 1(1), 56-62

Stoddart,T. Abrams, R., Gasper, E.,\& Canaday, D. (2000). Concept maps as assessment in science inquiry learning report of methodology. Journal of Science Education,22(12), 1221-1246.

Saeidi, A., Seif, A., Asadzadeh, H., \& Ebrahimi, S. (2012). The Effect of studying through Concept Maps on the comprehension of the Third-Year High School Students. Journal of Information and Communication Technology in Education, 3(1), 131-143 
Seif, A. (2002). Educational Psychology (Learning in education) book. AGAH Publisher.

Seif, A. (2005). Comparison of effectiveness Methods of presenting and preparing concept maps on comprehension. Journal of School Psychology, 3(2), 125-143

Sánchez, J. J. B. (2012), The analysis of errors in the solution of ordinary differential equations, Proceedings in ARSA-Advanced Research in Scientific Areas.

Trochim, W. M. K., Cook, J. A., \& Setze, R. J. (1994). Using Concept Mapping to Develop a Conceptual Framework of Staff's Views of a Supported Employment Program for Persons with Severe Mental Illness. Journal of Consulting and Clinical Psychology, 62 (4), 766-775

Tan, S., Erdimez, O., \& Zimmerman, R. (2017). Concept Mapping as a Tool to Develop and Measure Students' Understanding in Science. Acta Didactica Napocencia, 10(2), 109-122 


\section{Appendix}

Laplace concept map which includes Laplace transform, integral, derivative, and integral function; and inverse Laplace which includes the related theorems.

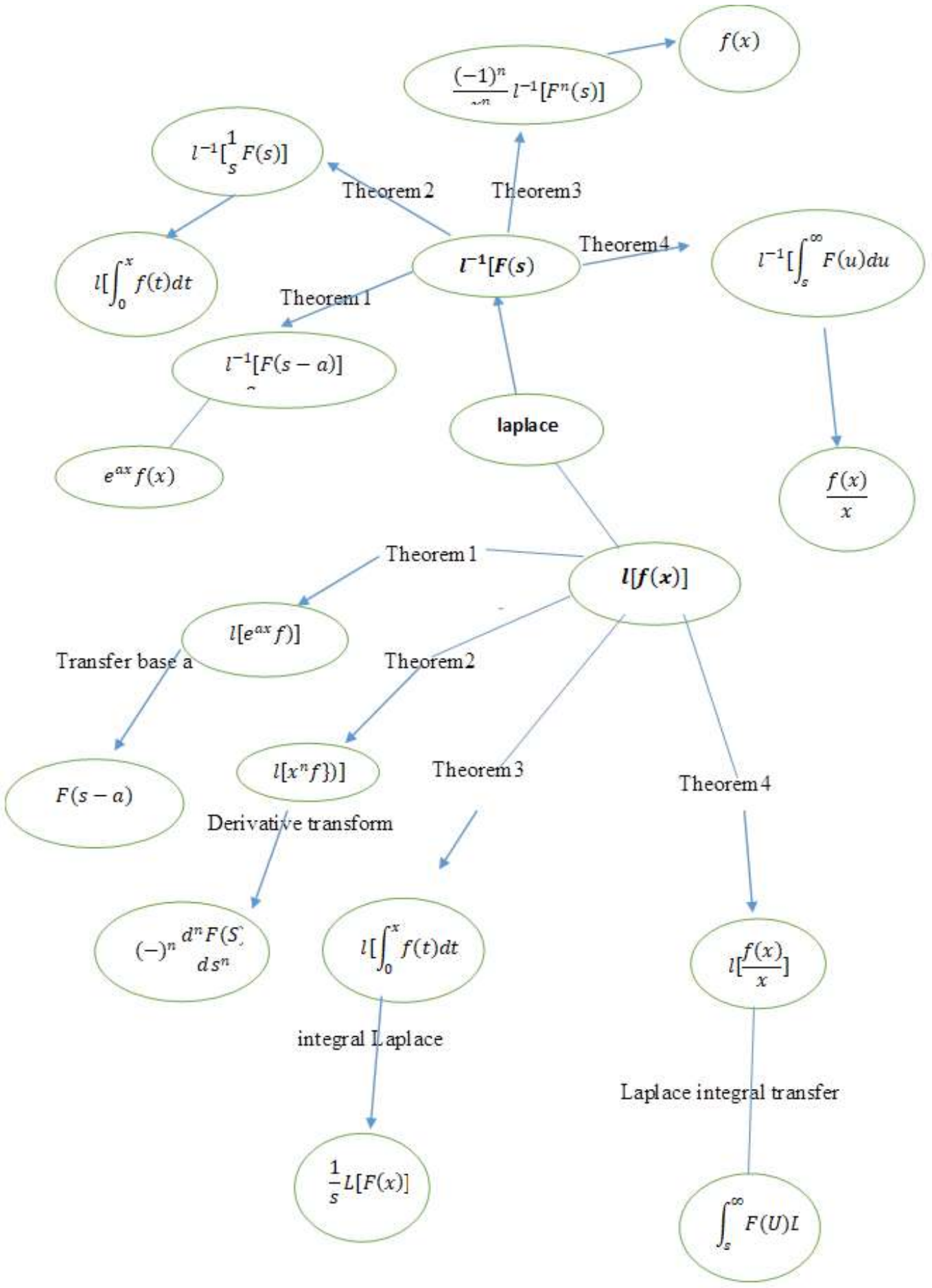

